\title{
OPEN Poly (red DSBR)/Al-ZnO modified carbon paste electrode sensor for dopamine: a voltammetric study
}

\author{
J. K. Shashikumara' ${ }^{1}$, B. E. Kumara Swamy ${ }^{1 凶}$, S. C. Sharma ${ }^{2,3}$, S. A. Hariprasad ${ }^{4}$ \& \\ Kaustubha Mohanty ${ }^{5}$
}

In the present work, the $\mathrm{ZnO}$ and $\mathrm{Al}-\mathrm{ZnO}$ nanoflakes (NFs) were synthesized by the co-precipitation process. The synthesized NFs were characterized by X-ray diffraction and field emission scanning electron microscopy. Energy dispersive X-ray spectrometer was explored for the elemental chemical compositions. The prepared NFs were taken for the modification of the electrode and developed the modified electrode for the electrochemical analysis of the dopamine (DOA) at pH 7.4. The Al-ZnO modified carbon paste electrode (MCPE) was electropolymerised by using textile dye red DSBR. The Po-RD/AI-ZnO MCPE exhibited good electrochemical sensor properties towards the electrochemical detection of DOA. Several factors such as the impact of speed rate $(u), \mathrm{pH}$ and concentration of the DOA were analyzed at the modified electrode. The great sensitivity was established to the fast electron-transfer kinetics and surface coverage of the DOA on the electrode. The prepared electrode exhibits satisfactory stability at the ambient conditions. The detection limit of $0.58 \mu \mathrm{M}$ was achieved for the DOA. The decorated sensor was stable, sensitive, selective, and reproducible and used in the analytical applications.

Now-a-days, several NFs have been developed and they show good active properties for the electrochemical studies. The metal oxide NFs have fabulous attention because of its easily-obtained and favorable sensing properties, specific surface areas, optimum optical and electronic properties, outstanding catalytic activities, great conductivities $^{1-5}$. Zinc oxide $(\mathrm{ZnO})$ is a massively intended nano-structured metal oxide and is an impressively inspected scientific inorganic material because of its special semiconducting and exclusive sensing properties to sense the various gases and vapors. It is additionally used in several fields of applications such as gas sensors, optoelectronic devices, variations, and transparent conducting electrodes. Now-a-days, numerous researchers are checking $\mathrm{ZnO}$ NFs to execute multidimensional phenomenal research and also to use it as a modifier due to its astounding surface properties like sensing, electronic, and catalytic properties ${ }^{6-11}$. Doping is one of the good and effective methods used to increase conductivity and it improves the sensing properties of metal-oxide semiconductors by altering the energy-band structure and morphology because dopants can afford electronic defects. A number of reports are obtainable on the improvement of the sensing properties of $\mathrm{ZnO}$ by adding different doping materials. The 'Al' is considered a promising dopant and shows low resistivity in the thin-film shape. Also, Al-doped $\mathrm{ZnO}$ thin films are of specific interest because of their less price of raw material, good electrical and optical properties for the applications in light-emitting diodes, organic sensors, mass production of photovoltaic devices, and liquid crystal display ${ }^{12-18}$.

Carbon paste electrodes (CPEs) have interesting advantages such as reproducibility, stability, and renewability of the surface which makes them one of the most attractive materials as working electrodes ${ }^{19,20}$. To date CPEs more applicable in wide areas such as pharmacological, biological, and environmental analysis, due to their low price when compared to other materials. CPE's electrochemical properties such as adsorption capacity, selectivity,

\footnotetext{
${ }^{1}$ Department of P.G. Studies and Research in Industrial Chemistry, Kuvempu University, Jnanasahyadri, Shankaraghatta, Shivamogga, Karnataka 577451, India. ${ }^{2}$ Director, National Assessment and Accreditation Council, (Work carried out as Honorary Professor, Jain University), Bangalore, Karnataka 560 069, India. ${ }^{3}$ School of Energy Science and Engineering, Indian Institute of Technology Guwahati, Guwahati 781039, India. ${ }^{4} J a i n$ Deemed-to-be University, Bangalore, Karnataka 560 069, India. ${ }^{5}$ Department of Chemical Engineering, Indian Institute of

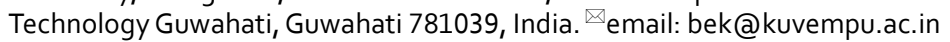




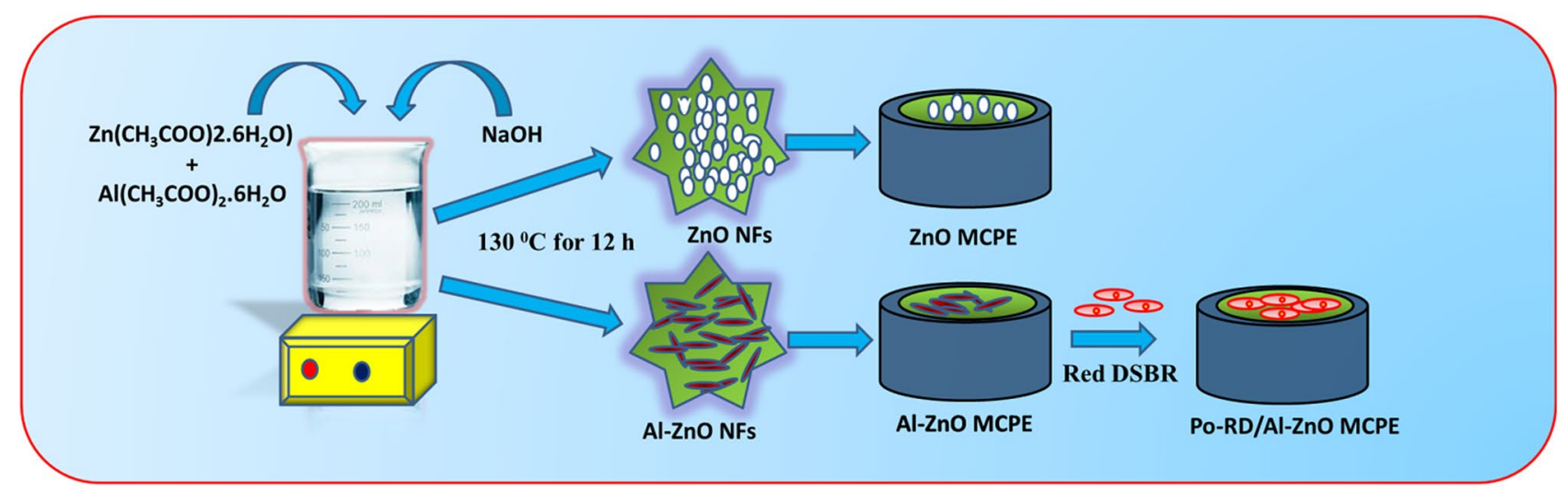

Figure 1. Schematic representation of the stepwise synthesis of NFs and fabrication of electrode.

and sensitivity can be enhanced by physical or chemical medications ${ }^{21,22}$. The reason to modify a CPE matrix is to obtain a new sensor with desired electrochemical properties.

DOA is the tremendously crucial to associative neuron communication in the human central nervous system as a chemical messenger. The deviation of DOA concentration in the human body may cause neurological disorders such as Parkinson's disease. Diseases are distorted the lives of people around the world through their deficiency of DOA in the human body for that reason developing a sensor for DOA is very significant ${ }^{23-26}$.

In this work, $\mathrm{ZnO}$ and $\mathrm{Al}-\mathrm{ZnO}$ NFs were synthesized by the co-precipitation method, the formation of the NFs were confirmed by XRD and FESEM with EDX. The synthesized NFs were used as the modifiers and Al-ZnO NFs were electropolymerised by Red DSBR. Finally, a poly (Red DSBR)/Al-ZnO modified Carbon Paste electrode (Po-RD/Al-ZnO MCPE) was developed. The developed electrode displayed good electrocatalytic activity towards DOA. The various parameters such as the effect of scan rate, $\mathrm{pH}$ and concentration of DOA were studied. The sensor can be used for the DOA assay in pharmaceutical samples.

\section{Experimental segment}

Materials selection and apparatus. Dopamine hydrochloride, uric acid (UA), ascorbic acid (AA), folic acid (FA), sodium hydroxide, $\mathrm{Na}_{2} \mathrm{HPO}_{4}$, zinc acetate hexahydrate $\left.\left[\mathrm{Zn}\left(\mathrm{CH}_{3} \mathrm{COO}\right)_{2} \cdot 6 \mathrm{H}_{2} \mathrm{O}\right)\right]$, aluminum acetate hexahydrate $\left[\mathrm{Al}\left(\mathrm{CH}_{3} \mathrm{COO}\right)_{2} \cdot 6 \mathrm{H}_{2} \mathrm{O}\right], \mathrm{NaH}_{2} \mathrm{PO}_{4}$ and ethanol were procured from Nice Chemicals Pvt. Ltd. (India). The silicon oil (Himedia), graphite powder (Loba Chemie) and Red DSBR (Astik Dyestuff Pvt. Ltd) were used directly as received along with other chemicals as listed above. Double distilled water was used as solvent throughout the experimental procedure. Structural analyses of the films were captured by FESEM and elemental chemical compositions were found out from EDX. The electrochemical research was carried on a voltammetric instrument of model CH Instrument-CHI 660c electrochemical workstation.

Preparation of $\mathrm{ZnO}$ and $\mathrm{Al}-\mathrm{ZnO}$ NFs. $\mathrm{ZnO}$ and 5\% Al-doped $\mathrm{ZnO}$ were synthesized by the co-precipitation technique. The host precursor was zinc acetate hexahydrate while doping one was the aluminum acetate hexahydrate. For synthesizing the undoped $\mathrm{ZnO} N F$, a suitable quantity of $\mathrm{Zn}\left(\mathrm{CH}_{3} \mathrm{COO}\right)_{2}$ was dissolved in 1:1 ratio of ethanol to water system under magnetic stirring for $20 \mathrm{~min}$ at the room temperature. Then, an aqueous $\mathrm{NaOH}$ solution was added to the above solution until the $\mathrm{pH}$ value reached 7.0. The resultant solution was continuously stirred for $2 \mathrm{~h}$ under the magnetic stirring. The precipitate obtained was centrifuged at $5000 \mathrm{rpm}$ for $4 \mathrm{~min}$ and washed many times with ethanol. The white solid was dried in a hot air oven at $130{ }^{\circ} \mathrm{C}$ for $12 \mathrm{~h}$. The obtained powder was then calcinated for $5 \mathrm{~h}$ at $600^{\circ} \mathrm{C}$ in a muffle furnace. The Al-doped $\mathrm{ZnO}$ NFs were synthesized using the same process with $5 \% \mathrm{Al}$ precursor (Fig. 1).

Setting up of the electrodes. The CPE was modified by taking $4 \mathrm{mg} \mathrm{ZnO}$ and $\mathrm{Al}-\mathrm{ZnO} \mathrm{NFs}$ in silicon oil and graphite powder $(70: 30 \mathrm{w} / \mathrm{w})$. Then this mixture was systematically mixed in an agate mortar for about $30 \mathrm{~min}$ and filled into a homemade Teflon cavity and polished by the soft paper ${ }^{27}$. Without NFs process is exactly similar to the bare carbon paste electrode (BCPE). The composite Po-RD/Al-ZnO MCPE developed by Al-ZnO MCPE was again fabricated by the electrodeposition of $1 \mathrm{mM}$ aqueous Red DSBR monomer (Fig. 2) accommodating with $0.1 \mathrm{M} \mathrm{NaOH}$ within the range of -0.8 to $1.1 \mathrm{~V}$ at the speed rate of $100 \mathrm{mV} \mathrm{s}^{-1}$ and then the electrode was cleaned with double distilled water ${ }^{28}$.

\section{Outcome and discussion}

XRD analysis. Figure 3 displays the XRD arrangements of the synthesized $\mathrm{ZnO}$ and Al-ZnO NFs. The sharp distinctive peaks were observed for both samples in the arrangements corresponding the perfect wurtzite structure of $\mathrm{ZnO}$ (JCPDS data card no: 89-0510). The achieved phase was pure and no peak was observed correspond to $\mathrm{Al}$ indicates that the $\mathrm{Al}$ atoms were effectively corroborate into $\mathrm{ZnO}$ lattice. Inset Fig. 3 displays small switch of the peaks towards lower $2 \theta$ value because of Al content. The dissimilarity in the ions size cause local distortion of the lattice due to specific residual stress inside the $\mathrm{NFs}^{29}$. Moreover intensity of all peaks reduced with doping 
<smiles>O=S(=O)(O)OCCOS(=O)(=O)c1c(S(=O)(=O)O)cc(S(=O)(=O)O)c2cc(S(=O)(=O)O)c(Nc3nc(Cl)nc(Nc4c(S(=O)(=O)O)cc5cc(S(=O)(=O)O)c(N=Nc6ccc(S(=O)(=O)O)cc6)c(O)c5c4O)n3)c(O)c12</smiles>

Figure 2. Structure of Red DSBR.

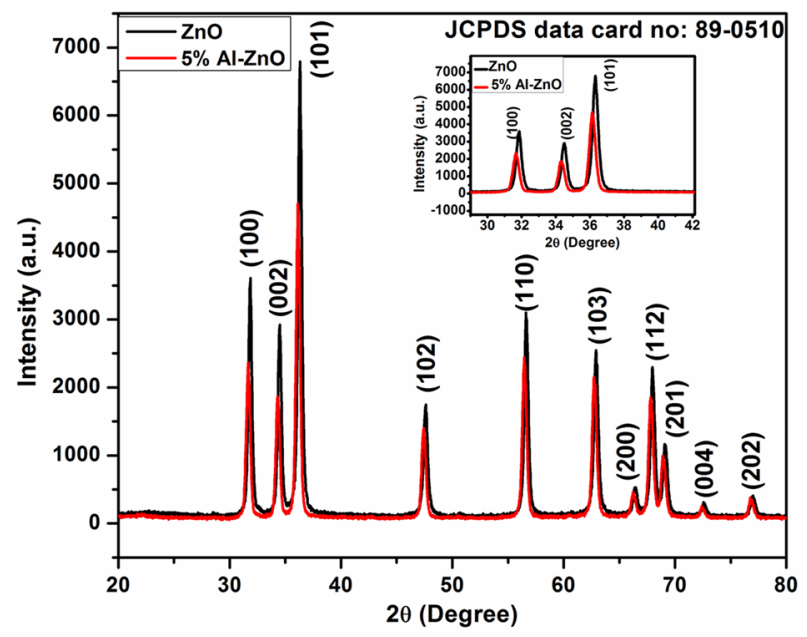

Figure 3. $\mathrm{XRD}$ patterns of $\mathrm{ZnO}$ and $5 \% \mathrm{Al}-\mathrm{ZnO}$ NFs. Inset shows the peak shifting character of the plane (100) (002) and (101) towards lower angle for Al-ZnO.

\begin{tabular}{|l|l|l|l|l|l|l|}
\hline \multirow{2}{*}{ Sample } & \multirow{2}{*}{} & & & & \multicolumn{3}{|l|}{$\begin{array}{l}\text { Lattice } \\
\text { parameters }\end{array}$} \\
\cline { 6 - 8 } & $\mathbf{2}\left(^{0}\right)$ & FWHM & Crystallite size & Micro-strain $(\boldsymbol{\varepsilon})$ & a & c \\
\hline $\mathrm{ZnO}$ & 36.4101 & 0.2841 & 30.76 & 0.0038 & 3.2501 & 5.2113 \\
\hline $\mathrm{Al}-\mathrm{ZnO}$ & 36.3473 & 0.3368 & 25.93 & 0.0045 & 3.2523 & 5.2193 \\
\hline
\end{tabular}

Table 1. Structural parameter derived from XRD data.

indicated the decrease in the crystallinity of ZnO NFs because of the corroboration of defects in the lattice site ${ }^{30}$. Scherrer's Eq. (1) ${ }^{31}$ was employed to calculate the average crystallite size of the $\mathrm{ZnO}$ and Al-ZnO NFs.

$$
D=\frac{k \lambda}{\beta_{h k l} \cos \theta}
$$

where ' $\mathrm{k}$ ' was a constant of 0.94 , ' $\lambda$ ' was the $\mathrm{X}$-ray wavelength of $1.54060 \AA$ for $\mathrm{Cu}-\mathrm{Ka}, \theta$ was the Bragg diffraction angle, and ' $\beta$ ' was the full width half maxima. The calculated crystallite size of the NFs is presented in Table 1. It is evident from Table 1 that the increase of $\mathrm{Al}$ content resulted in decrease of average crystallite size. The reduction in the crystallite size was mainly due to distortion in the host lattice by the foreign impurities (i.e., $\mathrm{Al}^{3+}$ ) that decrease the nucleation and subsequent growth rate of ZnO NFs. Such type of decrease in crystallite size with increasing in $\mathrm{Al}$ dopant level in $\mathrm{ZnO}$ lattice was also reported by Zamiri et al. ${ }^{32}$. 

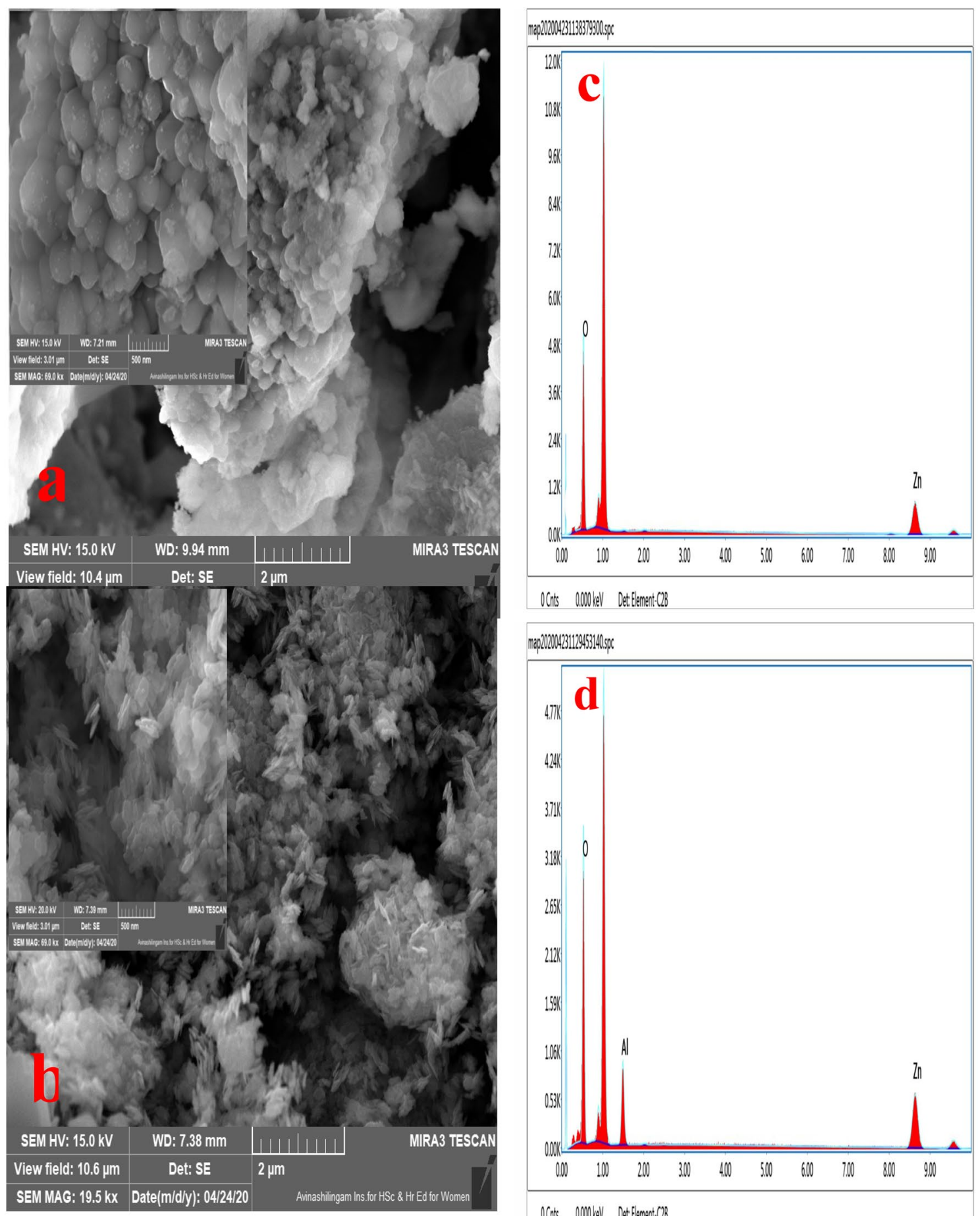

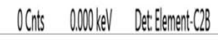

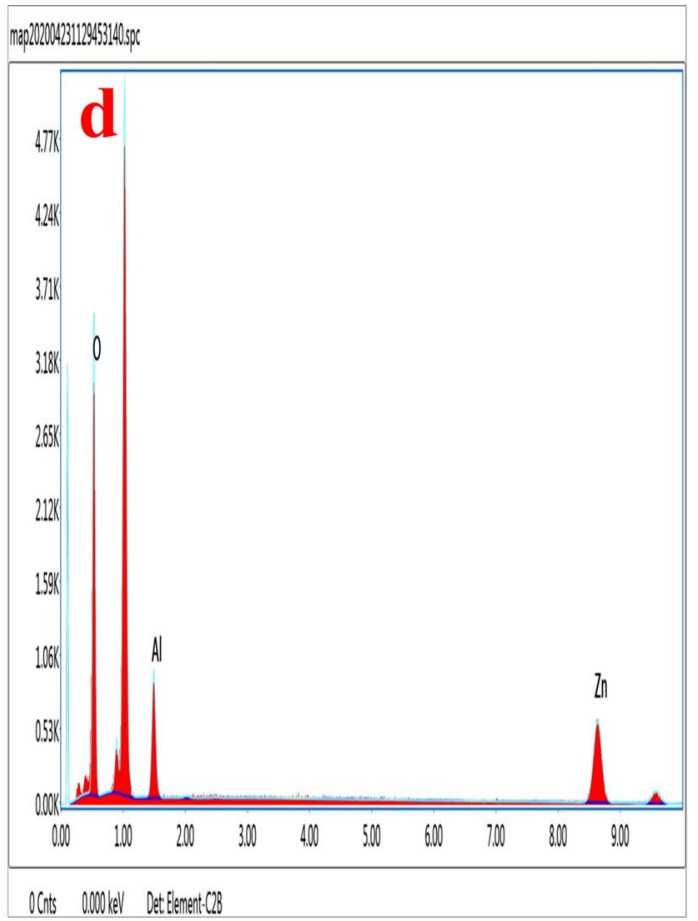

Figure 4. FESEM images of (a) ZnO NFs, (b) $5 \% \mathrm{Al}-\mathrm{ZnO}$ NFs, (c) EDX of ZnO NFs, (d) EDX of $5 \%$ Al NFs.

Morphological characterization. FESEM picture of the pure and Al-doped $\mathrm{ZnO}$ are depicted in Fig. 4a,b. It is exposed the surface of pure $\mathrm{ZnO}$ appearances like a cluster of spherical nanoparticles. Interestingly, after 5\% $\mathrm{Al}$ doping, the cluster of spherical nanoparticles of $\mathrm{ZnO}$ converted into NFs-like construction. Figure $4 \mathrm{c}$, d shows the EDXA spectra of the pure and Al-doped ZnO NFs. The appearance of well-defined peaks associated to $\mathrm{Zn}$, $\mathrm{O}$, and $\mathrm{Al}$ approves the effective doping of $\mathrm{Al}$ into $\mathrm{ZnO}$.

Electrochemical characterization. Figure 5 depicts the CV curve developed at a speed rate of $50 \mathrm{mV} \mathrm{s}^{-1}$ for MCPEs and $\mathrm{BCPE}$ disperse in $1 \mathrm{M} \mathrm{KCl}$ containing $1 \mathrm{mM} \mathrm{K}_{4}\left[\mathrm{Fe}(\mathrm{CN})_{6}\right]$ electrolyte. The electrode active surface area for the reversible reaction was calculated by accepting Randles-Sevcik Eq. (2) 


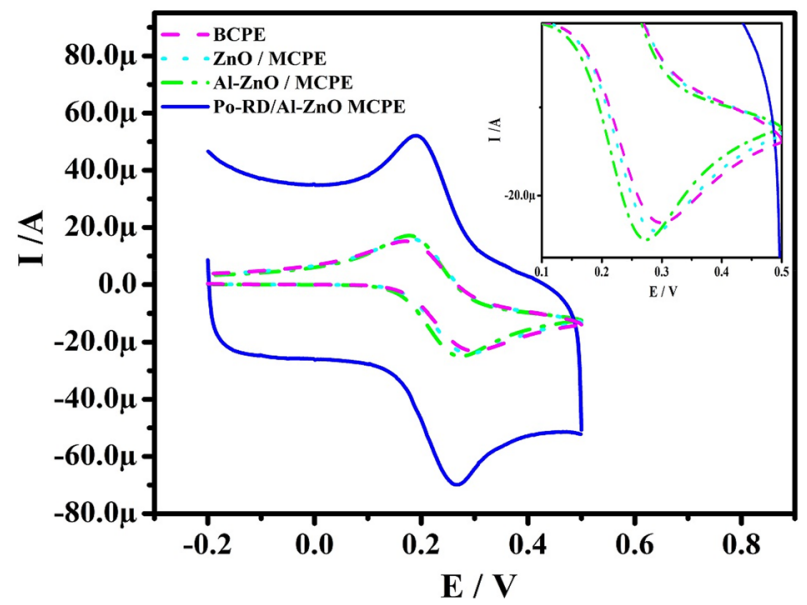

Figure 5. CVs of $1 \mathrm{mM}$ potassium ferrocyanide in $1 \mathrm{M} \mathrm{KCl}$ at speed rate $50 \mathrm{mV} \mathrm{s}^{-1}$.

\begin{tabular}{|l|l|l|}
\hline Electrodes & $\boldsymbol{\Delta E}(\mathbf{m V})$ & Active surface area $\left(\mathbf{c m}^{2}\right)$ \\
\hline BCPE & 129 & 0.0336 \\
\hline ZnO MCPE & 109 & 0.0382 \\
\hline Al-ZnO MCPE & 86 & 0.0406 \\
\hline Po-RD/Al-ZnO MCPE & 74 & 0.0572 \\
\hline
\end{tabular}

Table 2. Active surface area for electrodes.

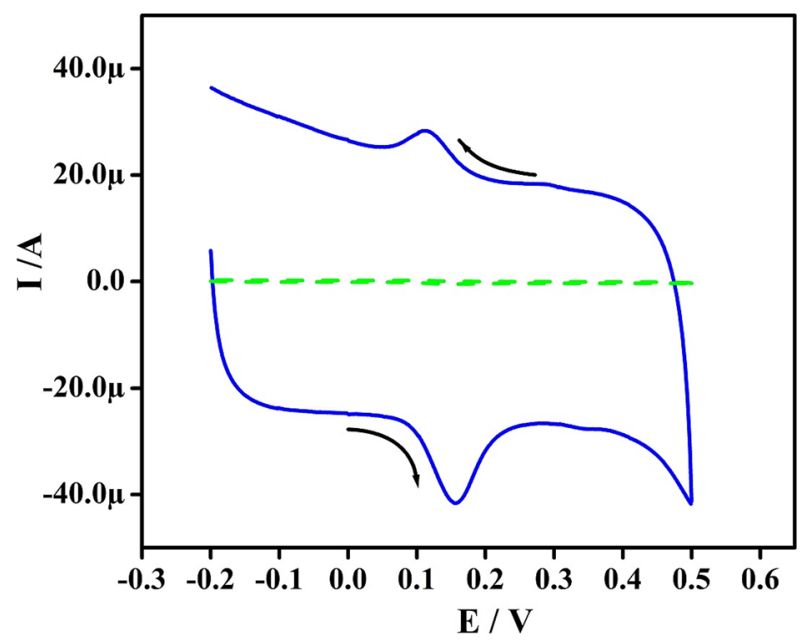

Figure 6. CVs of $5 \mu \mathrm{M}$ DOA in $0.2 \mathrm{M}$ PBS (pH 7.4) at BCPE and Po-RD/Al-ZnO MCPE at a speed rate of 50 $\mathrm{mV} \mathrm{s}^{-1}$.

$$
\mathrm{I}_{\mathrm{p}}=\left(2.69 \times 10^{5}\right) \mathrm{n}^{3 / 2} \mathrm{AD}_{0}^{1 / 2} \mathrm{C}_{0} v^{1 / 2}
$$

where Ip is the peak current, $v$ and A are the scan rate and area of the working electrode respectively, $\mathrm{n}$ is the number of electrons exchanged. The Po-RD/Al-ZnO MCPE exhibits excellent current response and acceptably redox peak potential separation $(\Delta \mathrm{E})$ decreases for Po- $\mathrm{RD} / \mathrm{Al}-\mathrm{ZnO}, \mathrm{Al}-\mathrm{ZnO}$, and $\mathrm{ZnO} \mathrm{MCPEs}$ compared to $\mathrm{BCPE}$ and also active surface area increased for MCPEs results presented in Table 2. Hence, the result recommends that the Po-RD/Al-ZnO MCPE possessed good electrocatalytic activity.

Electrochemical response for DOA at Po-RD/AI-ZnO MCPE. Figure 6 exhibits a CV profile of $5 \mu \mathrm{M}$ DOA at BCPE \& Po-RD/Al-ZnO MCPE in 0.2 M phosphate buffer solution (PBS) (pH 7.4). The Po-RD/Al-ZnO 


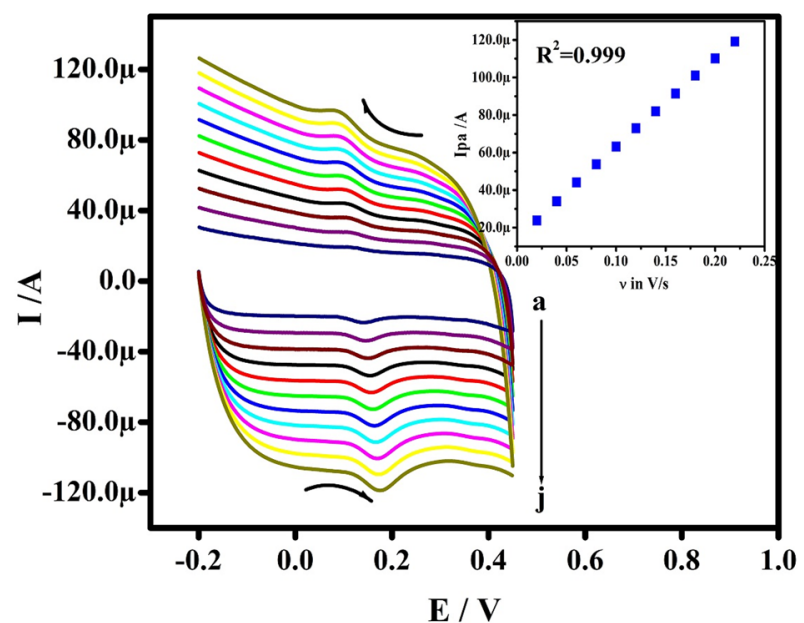

Figure 7. CVs of $5 \mu \mathrm{M}$ DOA in $0.2 \mathrm{M} \mathrm{PBS}$ of $\mathrm{pH} 7.4$ at Po-RD/Al-ZnO MCPE at numerous speed rates (a-j; $20-200 \mathrm{mV} \mathrm{s}^{-1}$ ). Inset graph is Ipa $\mathrm{v} / \mathrm{s} v$.

\begin{tabular}{|l|l|l|}
\hline $\mathbf{v} / \mathbf{m V} / \mathbf{s}$ & $\Delta \mathbf{E p} / \mathbf{m V}$ & $\mathbf{k}^{\circ}\left(\mathbf{s}^{-1}\right)$ \\
\hline 20 & 29 & 0.45556 \\
\hline 40 & 37 & 0.83148 \\
\hline 60 & 43 & 1.16453 \\
\hline 80 & 50 & 1.43328 \\
\hline 100 & 57 & 1.65379 \\
\hline 120 & 60 & 1.91764 \\
\hline 140 & 63 & 2.16181 \\
\hline 160 & 67 & 2.36019 \\
\hline 180 & 89 & 2.06471 \\
\hline 200 & 81 & 2.51385 \\
\hline
\end{tabular}

Table 3. Heterogeneous rate constant of DOA at different speed rate.

MCPE exhibits hike in redox Ip and a slight shift in the potential but BCPE the DOA exhibits less current with extensive peaks. The obtained results showed that modified electrode exhibits marvelous performance and it decreased the $\Delta \mathrm{E}$ with enhancement in anodic peak current (Ipa). These results indicate the catalytic effect of the developed sensor on DOA analysis.

Consequence of speed rate. The impact of the potential speed rate $(v)$ on the electrochemical performance of the DOA was studied in PBS ( $\mathrm{pH} 7.4$ ) at Po-RD/Al-ZnO MCPE. When the $v$ was raised in the range from 20 to $200 \mathrm{mV} \mathrm{s}^{-1}$ then the peak current Ip hiked with a slender positive shift in the peak potential as presented in the Fig. 7. The figure of the current intensity variations in terms of speed rates display in inset Fig. 7 and it exhibits good linearity. The results demonstrate that the oxidation-reduction reaction of DOA is under the control of adsorption. The $\mathrm{k}^{0}$ values for DOA are recorded in Table 3 and it was carried out by the $\Delta \mathrm{E}$ from the investigational data and Eq. $(3)^{33}$

$$
\Delta \mathrm{Ep}=201.39 \log \left(v / \mathrm{k}^{0}\right)-301.78
$$

Repercussion of concentration and influence of solution pH. Figure 8A depicted the CV's of DOA at Po-RD/Al-ZnO MCPE for different concentrations. The concentration of varied beginning in PBS (pH 7.4). The Ip of DOA hiked with hiking the concentration. The design of Ipa versus DOA concentration exhibits good linearity (Fig. 8B) and the lower limit of detection (LLOD) and limit of quantification (LOQ) is determined according to Eqs. $(4,5)^{34}$ and are presented in Table $4^{35-50}$.

$$
\mathrm{LLOD}=3 \mathrm{~S} / \mathrm{M}
$$



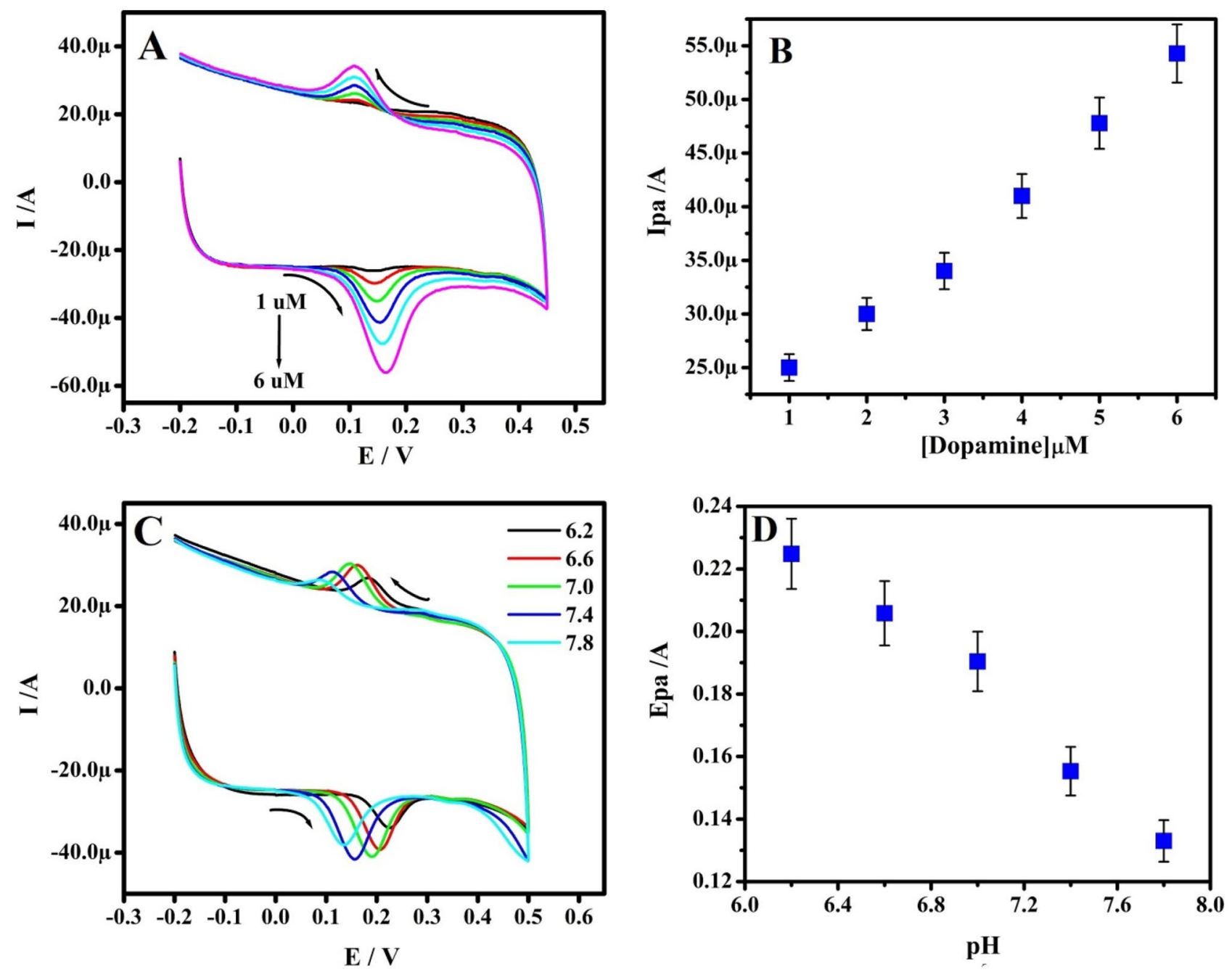

Figure 8. (A) CVs of DOA in 0.2 M PBS (pH 7.4) at Po-RD/Al-ZnO MCPE with various concentrations $(1-6 \mu \mathrm{M})$. (B) The plot of Ipa v/s concentration OF DOA. (C) CVs for different pH of $5 \mu \mathrm{M}$ DOA in $0.2 \mathrm{M}$ PBS. (D) Plot of Epa v/s pH.

\begin{tabular}{|l|l|l|l|l|}
\hline Sl. no & Electrodes & LLOD $(\mu \mathrm{M})$ & Method & References \\
\hline 01 & Au/Gr-Au & 30 & SW & 35 \\
\hline 02 & Pt-Au hybrid & 24 & CV & 36 \\
\hline 03 & CTAB/CPE & 11.0 & DPV & 37 \\
\hline 04 & Fc-MCPE & 9.4 & CV & 38 \\
\hline 05 & poly (sudan III)/MCPE & 9.3 & CV & 39 \\
\hline 06 & SWCNT/GCE & 7.0 & DPV & 40 \\
\hline 07 & Metallothioneins self-assembled gold electrode & 6.0 & CV & 41 \\
\hline 08 & LDH/CILE & 5.0 & DPV & 42 \\
\hline 09 & Ag-reduced GO/GCE & 5.4 & LSV & 43 \\
\hline 10 & Poly-VA/MWCNT/GCE & 4.5 & CV & 44 \\
\hline 11 & Ag/Ag2S-CNT-Nafion & 4.7 & DPV & 45 \\
\hline 12 & BPVCM-e/MWCNT/GCE & 2.25 & CV & 46 \\
\hline 13 & Poly(amido black) MCPE & 2.03 & CV & 47 \\
\hline 14 & CTAB-GO/MWNT & 1.5 & DPV & 48 \\
\hline 15 & Au/RGO & 1.4 & DPV & 49 \\
\hline 16 & ERGO & 0.5 & DPV & 50 \\
\hline 17 & Po-RD/Al-ZnO MCPE & 0.58 & CV & Present work \\
\hline
\end{tabular}

Table 4. Comparative analytical performance electrode for DOA. 

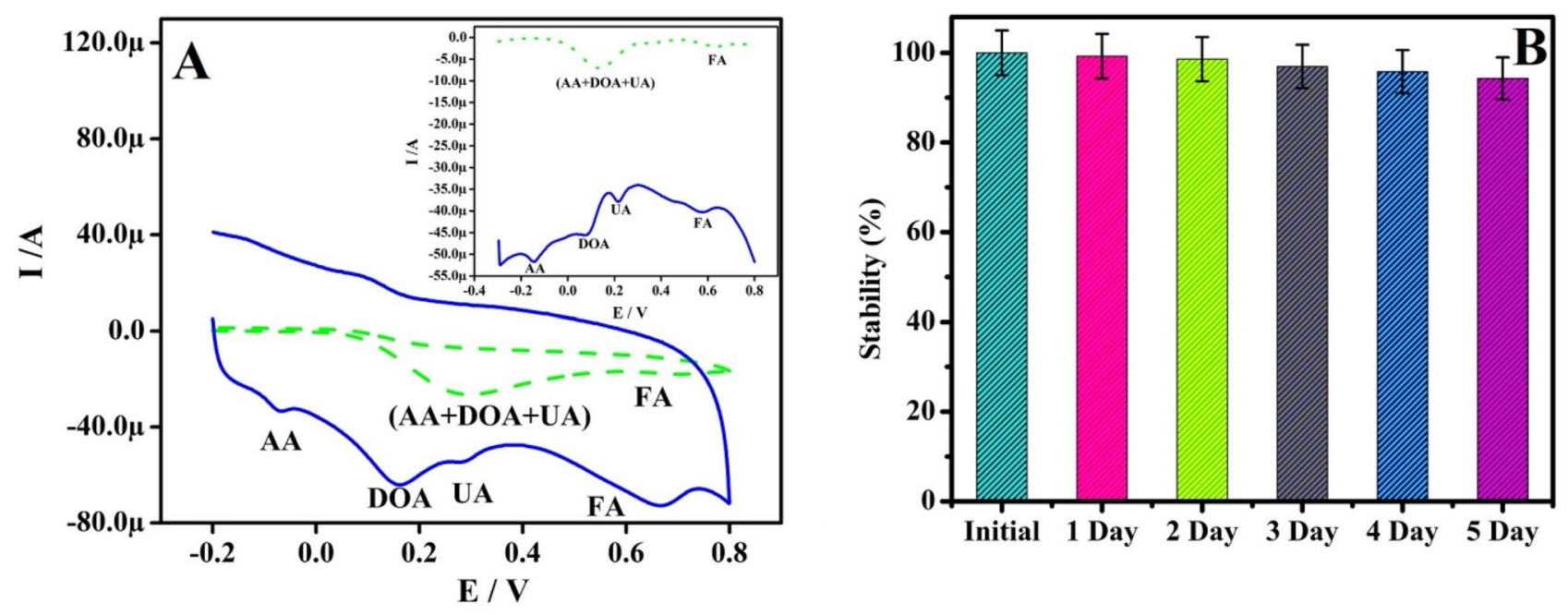

Figure 9. (A) CVs for selectivity analysis AA $(1 \mathrm{mM})$, DOA $(1 \mu \mathrm{M})$, UA $(1 \mu \mathrm{M})$ and FA $(10 \mu \mathrm{M})$ at BCPE and Po-RD/Al-ZnO MCPE at a speed rate of $50 \mathrm{mV} \mathrm{s}^{-1}$. (B) Stability of Po-RD/Al-ZnO MCPE toward DOA at different time intervals.

$$
\mathrm{LOQ}=10 \mathrm{~S} / \mathrm{M}
$$

where $S$ and $M$ specifies the standard deviation and slope.

The CV's profile for DOA at Po-RD/Al-ZnO MCPE in 0.2 M PBS range 6.2-7.8 portrayed in Fig. 8C. The anodic peak potential (Epa) was lifted towards the negative path with rising in $\mathrm{pH}$ and extreme current singles gained at 7.4. The Fig. 8D portrayed the linear establishment between Epa and $\mathrm{pH}$ lead to the slope of $58 \mathrm{mV}$ for the DOA. The corresponding $\mathrm{pH}$ equation is $\mathrm{Epa}(V)=-0.0585 \mathrm{pH}+0.5915, R^{2}=0.999(\mathrm{DOA})$. The achieved slope is nearby to the Nernstiant value for the same number of electrons and protons that are involved in the reactions.

Success of selectivity and reproducibility. The CV's profile for the mixture of Ascorbic acid (AA) $(1 \mathrm{mM})$, DOA $(1 \mu \mathrm{M})$, Uric acid (UA) $(1 \mu \mathrm{M})$ and, Folic acid (FA) $(10 \mu \mathrm{M})$ in $0.2 \mathrm{M}$ PBS (pH 7.4) at BCPE and Po-RD/Al-ZnO MCPE are presented in Fig. 9a. The CVs responses for analytes with short current signals were signifying the poor selectivity and intensity of the BCPE. Nevertheless, Po-RD/Al-ZnO MCPE is the ability to separate the oxidation potential of mixed analytes. This outcome was identifying selectivity Po-RD/Al-ZnO $\mathrm{MCPE}$. The reproducibility of Po-RD/Al-ZnO MCPE was also investigated afterward being kept at the room temperature for 5 days (Fig. 9b). It was found that the current signals recollected $99.25 \%$ after first day early current response and the peak potentials were almost unaffected. Likewise second to fifth day current signals almost recollected. This result shows the reproducibility of Po-RD/Al-ZnO MCPE.

Interference study and analytical application. The interference study was accomplished in the combination of samples having AA $(1 \mathrm{mM})$, DOA $(1 \mu \mathrm{M}), \mathrm{UA}(1 \mu \mathrm{M})$ and FA $(10 \mu \mathrm{M})$ at the Po-RD/Al-ZnO MCPE by DPVs. Figure 10a shows that the Ip of DOA was increased with increased concentrations starting 1-6 $\mu \mathrm{M}$ by custody of the constant concentration of AA, UA, and FA. Similarly, UA concentration was varied and its Ip increased with the concentration (Fig. 10b). These consequences showed the stability of Po-RD/Al-ZnO MCPE. The determination of DOA in pharmaceutical sample was studied by CV for practical ability. The Po-RD/Al$\mathrm{ZnO} \mathrm{MCPE}$ was performed for the determination of DOA in dopamine hydrochloride injection. The samples were analyzed by standard addition method. The results were found to be satisfactory as revealed from Table 5 . This showed a promising application in the biological field.

\section{Conclusion}

In the present work, $\mathrm{ZnO}$ and $\mathrm{Al}-\mathrm{ZnO}$ NFs were synthesized by co-precipitation method and used as the sensor for the DOA. The developed and decorated Po-RD/Al-ZnO MCPE exhibited good current response towards the DOA. The speed rate effect was established as adsorption-controlled electrode process. The $\mathrm{pH}$ study exposed participation of equal number of protons and electrons in the redox mechanism. The detection limit of $0.58 \mu \mathrm{M}$ was achieved for DOA Po-RD/Al-ZnO MCPE can separate the oxidation potential of AA, DOA, UA, and FA with large potential difference compared to BCPE. Po-RD/Al-ZnO MCPE showed $99.25 \%$ reproducibility. The synthesized Po-RD/Al-ZnO MCPE is a promising electrode material for the sensor applications. The recovery values clearly validated that the real time monitoring of DOA in pharmaceuticals samples has suitable medium for practical application. 

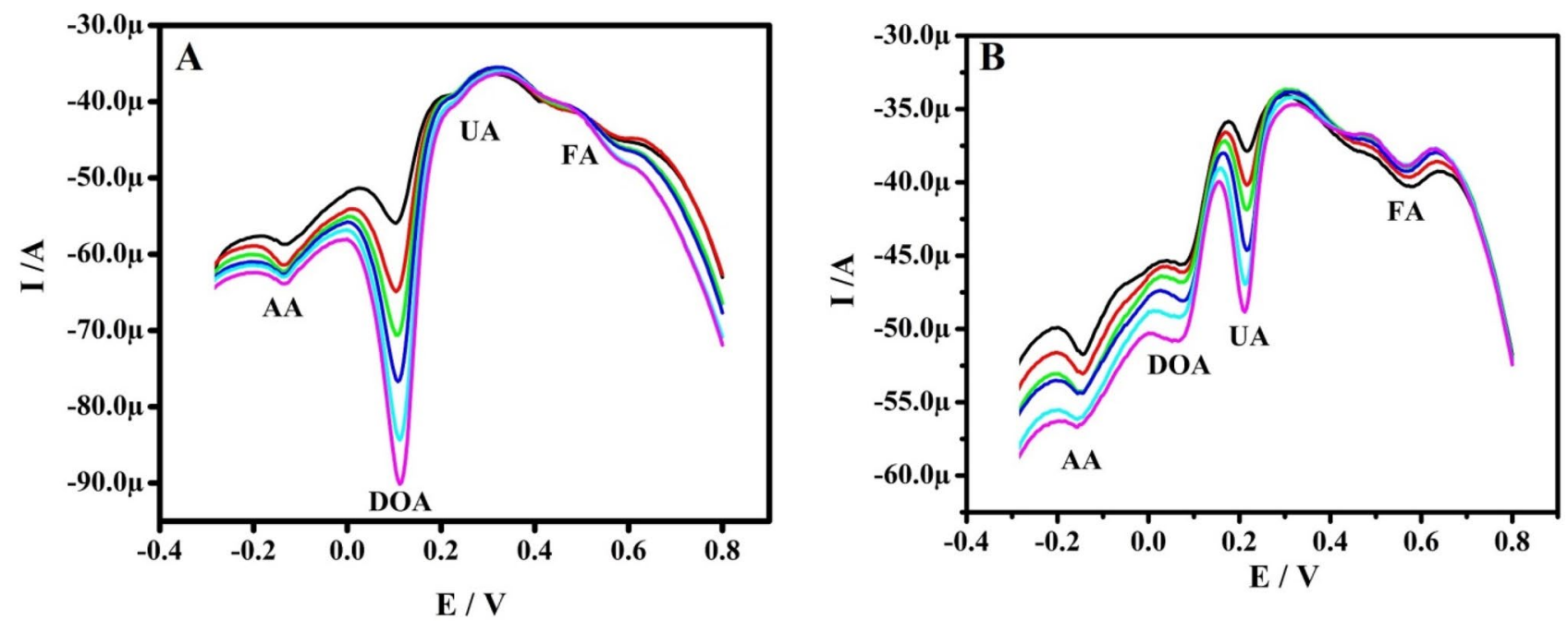

Figure 10. (A) DPVs got for different of concentration 1-6 $\mu \mathrm{M}$ DOA in PBS (pH 7.4) with AA (1 mM), UA $(1 \mu \mathrm{M})$ and FA $(10 \mu \mathrm{M})$ at Po-RD/Al-ZnO MCPE. (B) DPVs got for different of concentration 1-6 $\mu \mathrm{M}$ UA in PBS (pH 7.4) with AA $(1 \mathrm{mM})$, DOA $(1 \mu \mathrm{M})$ and FA $(10 \mu \mathrm{M})$ at Po-RD/Al-ZnO MCPE.

\begin{tabular}{|l|l|l|l|}
\hline Sample & Sample added $(\boldsymbol{\mu M})$ & Found $(\boldsymbol{\mu M})$ & Recovery $(\%)$ \\
\hline \multirow{4}{*}{ DOA } & 5 & 4.93 & 98.64 \\
\cline { 2 - 4 } & 10 & 9.94 & 99.4 \\
\cline { 2 - 4 } & 15 & 14.87 & 99.13 \\
\cline { 2 - 4 } & 20 & 19.82 & 99.1 \\
\hline
\end{tabular}

Table 5. Detection of DOA real sample $(n=4)$.

Received: 21 April 2021; Accepted: 15 June 2021

Published online: 12 July 2021

\section{References}

1. Maziarz, $\mathrm{W}$. $\mathrm{TiO}_{2} / \mathrm{SnO}_{2}$ and $\mathrm{TiO}_{2} / \mathrm{CuO}$ thin-film nano-heterostructures as gas sensors. Appl. Surf. Sci. 480, 361-370 (2019).

2. Gong, Y. et al. Enhanced acetone sensing properties of Pt@Al-doped ZnO core-shell nanoparticles. Sens. Actuators B Chem. 20, 20 (2020).

3. Bochenkov, V. E. \& Sergeev, G. B. Sensitivity, selectivity, and stability of gas-sensitive metal-oxide nanostructures. In Metal Oxide Nanostructures and Their Applications, Vol 3 31-52 (American Scientific Publishers, 2010).

4. Miller, D. R., Akbar, S. A. \& Morris, P. A. Nanoscale metal oxide-based heterojunctions for gas sensing: A review. Sens. Actuators B Chem. 204, 250-272 (2014).

5. Kim, H.-J. \& Lee, J.-H. Highly sensitive and selective gas sensors using p-type oxide semiconductors: Overview. Sens. Actuators B Chem. 192, 607-627 (2014).

6. Shetti, N. P. et al. A novel electrochemical sensor for detection of molinate using ZnO nanoparticles loaded carbon electrode. Electroanalysis 31, 1040-1049 (2019).

7. Chang, F. C., Zhu, Z., Luo, P. Y., Wu, R. J. \& Li, W. Au@ZnO core-shell structure for gaseous formaldehyde sensing at room temperature. Sens. Actuators B 199, 314-319 (2014).

8. Kang, S. K., Kang, D. Y., Park, J. W., Kyung, R. S. \& Tae, G. K. Work function-tunable ZnO/Ag/ZnO film as an effective hole injection electrode prepared via nickel doping for thermally activated delayed fluorescence-based flexible blue organic light-emitting diodes. Appl. Surf. Sci. 538, 148202 (2021).

9. Shixiang, D. et al. Core-shell nanostructured $\mathrm{ZnO} @ \mathrm{CoS}$ arrays as advanced electrode materials for high-performance supercapacitors. Electrochim. Acta 54, 136711 (2020).

10. RuiXu, KaiYang. YueZang, $\mathrm{ZnO} / \mathrm{Ag} / \mathrm{ZnO}$ multilayer transparent electrode for highly-efficient ITO-Free polymer solar cell. Curr. Appl. Phys. 20, 425-430 (2020).

11. Kong, H. \& Lee, H.-Y. High performance flexible transparent conductive electrode based on $\mathrm{ZnO} / \mathrm{AgOx} / \mathrm{ZnO}$ multilayer. Thin Solid Films 696, 137759 (2020).

12. Palmer, M. et al. Dataset of N-doped CuO:NiO mixed oxide thin film sensor for glucose oxidation. Data Brief. 33, 106408 (2020).

13. Hagedorn, K. et al. Catalytically doped semiconductors for chemical gas sensing: Aerogel-like aluminum-containing zinc oxide materials prepared in the gas phase. Adv. Funct. Mater. 26, 3424-3513 (2016).

14. Das, S., Girija, K. G., Debnath, A. K. \& Vatsa, R. K. Enhanced $\mathrm{NO}_{2}$ and $\mathrm{SO}_{2}$ sensor response under ambient conditions by polyol synthesized Ni doped $\mathrm{SnO}_{2}$ nanoparticles. J. Alloys Compd. 854, 157276 (2021).

15. Indrajith Naik, E., Bhojya Naik, H. S., Sarvajith, M. S. \& Pradeepa, E. Co-precipitation synthesis of cobalt doped ZnO nanoparticles: Characterization and their applications for biosensing and antibacterial studies. Inorg. Chem. Commun. 130, 108678 (2021).

16. Zhao, C., Gong, H., Niu, G. \& Wang, F. Ultrasensitive $\mathrm{SO}_{2}$ sensor for sub-ppm detection using Cu-doped $\mathrm{SnO}_{2}$ nanosheet arrays directly grown on chip. Sens. Actuators B Chem. 324, 128745 (2020).

17. Singh, S. K. et al. Detection of ammonia gas molecules in aqueous medium by using nanostructured Ag-doped $\mathrm{ZnO}$ thin layer deposited on modified clad optical fiber. Phys. Status Sol. 216, 1900141 (2019). 
18. Hjiri, M. et al. Al-doped $\mathrm{ZnO}$ for highly sensitive $\mathrm{CO}$ gas sensors. Sens. Actuators B Chem. 196, 413-420 (2014).

19. Piovesan, J. V., Santana, E. R. \& Spinelli, A. A carbon paste electrode improved with poly (ethylene glycol) for tannic acid surveillance in beer samples. Food Chem. 326, 127055 (2020).

20. Saleh, T. A., Abdur, K. \& Rahim, M. M. Electrochemical sensor for the determination of ketoconazole based on gold nanoparticles modified carbon paste electrode. J. Mol. Liq. 256, 39-48 (2018).

21. Rahim, A. M. A. \& Gaber, A. A. A. Fabrication and characterization of extrinsic electrochemically modified graphite reinforcement carbon paste electrode for selective determination of $\mathrm{Cu}(\mathrm{II})$ in trace levels. Appl. Surf. Sci. Adv. 2, 100031 (2020).

22. Cariati, L. S. S. \& Buoro, R. M. Evaluation of ionic natural deep eutectic solvents (NADES) modified binders towards the chemical properties of carbon paste electrodes. Electrochem. Commun. 109, 106605 (2019).

23. Shukla, S. K., Lavon, A., Shmulevich, O. \& Ben-Yoav, H. The effect of loading carbon nanotubes onto chitosan films on electrochemical dopamine sensing in the presence of biological interference. Talanta 181, 57-64 (2018).

24. Oren, T., Birel, O. \& Anık, U. Electrochemical determination of dopamine using a novel perylenediimide-derivative modified carbon paste electrode. Anal. Lett. 51, 1680-1693 (2018).

25. Fang, J., Xie, Z., Wallace, G. \& Wang, X. Co-deposition of carbon dots and reduced graphene oxide nanosheets on carbon-fiber microelectrode surface for selective detection of dopamine. Appl. Surf. Sci. 412, 131-137 (2017).

26. Sandoval-Rojas, A. P., Cortés, M. T. \& Hurtado, J. Electrochemical synthesis of poly (3,4-ethylenedioxythiophene) doped with a new bis(pyrazolyl)methane disulfonate and its behavior towards dopamine detection. J. Electroanal. Chem. 837, 200-207 (2019).

27. Ashoka, N. B., Swamy, B. E. K. \& Jayadevappa, H. Nanorod $\mathrm{TiO}_{2}$ sensor for dopamine: A voltammetric study. New J. Chem. 41, 11817 (2017).

28. Rashti, A., Moncada, J., Zhang, X., Carrero, C. A. \& Oh, T. S. Thermally grown copper nanowire electrodes modified by electropolymerization. Mater. Chem. Phys. 231, 168-172 (2019).

29. Islam, M. R., Rahman, M., Farhad, S. F. U. \& Podder, J. Structural, optical and photocatalysis properties of sol-gel deposited Aldoped $\mathrm{ZnO}$ thin films. Surf. Interfaces 16, 120-126 (2019).

30. Karmakar, R., Neogi, S. K., Banerjee, A. \& Bandyopadhyay, S. Appl. Surf. Sci. 263, 671 (2012).

31. Naik, E. I., Naik, H. S. B., Viswanath, R., Kirthan, B. R. \& Prabhakara, M. C. Effect of zirconium doping on the structural, optical, electrochemical and antibacterial properties of ZnO nanoparticles prepared by sol-gel method. Data Collect. 29, 100505 (2020).

32. Zamiri, R., Singh, B., Belsley, M. S. \& Ferreira, J. M. F. Structural and dielectric properties of Al-doped ZnO nanostructures. Ceram. Int. 40, 6031-6036 (2014).

33. Shashikumara, J. K., Kumara Swamya, B. E. \& Sharma, S. C. A simple sensing approach for the determination of dopamine by poly (Yellow PX4R) pencil graphite electrode. Chem. Data Collect. 27, 100366 (2020).

34. Shashikumara, J. K. et al. Effect of RGO- $\mathrm{Y}_{2} \mathrm{O}_{3}$ and RGO- $\mathrm{Y}_{2} \mathrm{O}_{3}: \mathrm{Cr}^{3+}$ nanocomposite sensor for dopamine. Sci. Rep. 11, 9372 (2021).

35. Pruneanu, S. et al. The influence of uric and ascorbic acid on the electrochemical detection of dopamine using graphene-modified electrodes. Electrochim. Acta 154, 197 (2015).

36. Thiagarajan, S. \& Chen, S. M. Preparation and characterization of Pt Au hybrid film modified electrodes and their use in simultaneous determination of dopamine, ascorbicacid and uric acid. Talanta 74(2), 212-222 (2007).

37. Corona-Avendano, S. et al. Influence of CTAB on the electrochemical behavior of dopamine and on its analytic determination in the presence of ascorbic acid. J. Appl. Electrochem. 40, 463 (2010).

38. Ali Kamyabi, M. \& Aghajanloo, F. Electrocatalytic response of dopamine at a CPE modified with ferrocene. Roat. Chem. Act. 82, 599-606 (2009).

39. Naik, T. S. S. K., Mwaurah, M. M. \& KumaraSwamy, B. E. Fabrication of poly (sudan III) modified carbon paste electrode sensor for dopamine: A voltammetric study. J. Electroanal. Chem. 834, 73 (2018).

40. Goyal, R. N. \& Singh, S. P. Simultaneous voltammetric determination of dopamine and adenosine using a single-walled carbon nano tube-MCPE. Carbon 46, 1556-1562 (2008).

41. Wang, Q., Li, N. \& Wang, W. Electrocatalytic response of dopamine at a metallothioneins self-assembled gold electrode. Anal. Sci. 18, 635 (2002).

42. Zhu, Z. et al. Electrochemical detection of dopamine on a Ni/Al layered double hydroxide modified carbon ionic liquid electrode. Sens. Actuators B 151, 146-152 (2010).

43. Kaur, B., Pandiyan, T., Satpati, B. \& Srivastava, R. Simultaneous and sensitive determination of ascorbic acid, dopamine, uric acid, and tryptophan with silver nanoparticles-decorated reduced graphene oxide modified electrode. Colloids Surf. B 111, 97-106 (2013).

44. Silva, L. V. D. et al. Amperometric sensor based on carbon nanotubes and electropolymerized vanillic acid for simultaneous determination of ascorbic acid, dopamine, and uric acid. J. Solid State Electrochem. 20, 2389-2393 (2016).

45. Chih, Y. K. \& Yang, M. C. Simultaneous detection of dopamine and ascorbic acid using silver. Taiwan Inst. Chem. Eng. 45, 833-839 (2014).

46. Liu, R. et al. A glassy carbon electrode modified with an amphiphilic, electroactive and photosensitive polymer and with multiwalled carbon nanotubes for simultaneous determination of dopamine and paracetamol. Microchim. Acta 183, 1543-1551 (2016).

47. Shashikumara, J. K., Kumara Swamy, B. E. \& Madhuchandra, H. D. Poly (amido black) modified carbon paste electrode sensor for dopamine in the presence of uric acid. Mater. Sci. Energy Technol. 3, 390-396 (2020).

48. Yang, Y. J. \& Li, W. K. CTAB functionalized graphene oxide/multiwalled carbon nanotube composite modified electrode for the simultaneous determination of ascorbic acid, dopamine, uric acid and nitrite. Sens. Actuators B Chem. 56, 300-306 (2014).

49. Wang, C. et al. A facile electrochemicalsensor based on reduced graphene oxide and Au nanoplates modified glassycarbon electrode for simultaneous detection of ascorbic acid, dopamine, anduric acid. Sens. Actuator B Chem 204, 302-309 (2014).

50. Yang, L., Liu, D., Huang, J. S. \& You, T. Y. Simultaneous determination of dopamine, ascorbic acid and uric acid at electrochemically reduced graphene oxide modified electrode. Sens. Actuators B Chem. 193, 166-172 (2014).

\section{Author contributions}

J.K.S.: electrochemical sensors experiments, formal analysis, writing—original draft. B.E.K.S.: conceptualization, supervision, writing—review and editing. S.C.S.: writing - review and editing. S.A.H.: writing—review and editing. K.M.: writing-review and editing.

\section{Competing interests}

The authors declare no competing interests.

\section{Additional information}

Correspondence and requests for materials should be addressed to B.E.K.S.

Reprints and permissions information is available at www.nature.com/reprints. 
Publisher's note Springer Nature remains neutral with regard to jurisdictional claims in published maps and institutional affiliations.

(c) (i) Open Access This article is licensed under a Creative Commons Attribution 4.0 International License, which permits use, sharing, adaptation, distribution and reproduction in any medium or format, as long as you give appropriate credit to the original author(s) and the source, provide a link to the Creative Commons licence, and indicate if changes were made. The images or other third party material in this article are included in the article's Creative Commons licence, unless indicated otherwise in a credit line to the material. If material is not included in the article's Creative Commons licence and your intended use is not permitted by statutory regulation or exceeds the permitted use, you will need to obtain permission directly from the copyright holder. To view a copy of this licence, visit http://creativecommons.org/licenses/by/4.0/.

(C) The Author(s) 2021 